\title{
Radiative MHD flow over a vertical plate with convective boundary condition
}

\author{
Christian John Etwire*, Yakubu Ibrahim Seini \\ Faculty of Mathematical Sciences, University for Development Studies, P.O. Box 1350, Tamale - Ghana
}

Email Address:

jecpapa@yahoo.com (C. J. Etwire), yakubuseini@yahoo.com (Y. I. Seini)

To cite this article:

Christian John Etwire, Yakubu Ibrahim Seini. Radiative MHD Flow over a Vertical Plate with Convective Boundary Condition. American Journal of Applied Mathematics. Vol. 2, No. 6, 2014, pp. 214-220. doi: 10.11648/j.ajam.20140206.14

\begin{abstract}
This paper investigates the effect of thermal radiation on magneto hydrodynamic (MHD) flow over a vertical plate with convective boundary conditions. The governing partial differential equations were transformed into coupled nonlinear differential equations which were solved numerically using the fourth order Runge-Kutta algorithm with a shooting method. Numerical results for the skin friction coefficient, the rate of heat transfer represented by the local Nusselt number and the plate surface temperature were presented whilst the velocity and temperature profiles illustrated graphically and analyzed. The effects of the Biot number, Grashof number, magnetic field parameter, Eckert number, Prandtl number and radiation parameter on the flow field were discussed.
\end{abstract}

Keywords: Convective, Radiation, Magneto Hydrodynamic, Eckert Number, Magnetic Field, Biot Number

\section{Introduction}

The study of MHD flow over a vertical plate with convective surface boundary conditions has attracted much interest in recent years due to its significance in many engineering industrial processes. The industrial applications include: glass-fiber production, condensation process of metallic plate in a cooling bath and glass and aerodynamic extrusion of plastic sheets. These among other applications led researchers to investigate various aspect of the problem. Ajadi, et al. [1] studied the slip boundary layer flow of nonNewtonian fluid over a flat plate with convective thermal boundary condition. Abel and Mareppa [2] looked at MHD flow and heat transfer of the mixed hydrodynamic and thermal slip over a linear vertically stretching sheet whilst Seini and Makinde [3] investigated the hydromagnetic flow with dufour and soret effects past a vertical plate embedded in porous media. Abbasi et al. [4] looked at an analytic solution of hydrodynamic and thermal boundary layers over a flat plate in a uniform stream of fluid with convective surface boundary conditions. Similarity solution of hydromagnetic heat and mass transfer over a vertical plate with a convective surface boundary condition was investigated by Makinde [5]. Thermal radiation effects are of great significance in the field of space technology and in processes involving high temperatures. For instance, some devices for space applications are designed to operate at high temperature levels in order to achieve high thermal efficiency. Radiation is also considered especially when calculating thermal effects in devices such as a nuclear power plant, gaseous nuclear rockets and rocket nozzles. Recent advancement in hypersonic flights, gas cooled nuclear reactors, rocket combustion chambers and missile reentry, have perhaps shifted researchers' attention to thermal radiation as a mode of energy transfer, and emphasize the need for improved understanding of radiative transfer in these processes. The effect of thermal radiation on heat and mass transfer of a variable viscosity fluid past a vertical porous plate permeated by a transverse magnetic field was reported in Makinde and Ogulu [6]. Ghaly and Elbarbary [7] investigated the effects of radiation on MHD free convection flow of a gas at a stretching surface with uniform free stream. Emad [8] studied radiation effect on heat transfer in an electrically conducting fluid at a stretching surface with uniform free stream. Radiation effect on MHD stagnation point flow in a Nanofluid was investigated by Yazdi et al [9]. Mazumdar and Deka [10] analyzed MHD flow past an impulsively started infinite vertical plate in the presence of thermal radiation. Srinivas and Muthuraj [11] discussed the effects of thermal radiation and space porosity on MHD mixed convection flow 
in a vertical channel using homotopy analysis method. Emmanuel et al. [12] investigated the hydromagnetic flow over a flat surface in the presence of radiation with viscous dissipation and convective boundary conditions. Hossain and Takhar [13] studied the effect of radiation using the Rosseland diffusion approximation, which led to non-similar solutions for the forced and free convection flow of an optically dense fluid from vertical surfaces with constant free stream velocity and surface temperature. Imoro et al. [14] analyzed the heat and mass transfer over a vertical surface with convective boundary conditions in the presence of viscous dissipation and nth order chemical reaction while Seini and Makinde [15] investigated the boundary layer flow near stagnation-points on a vertical surface with slip in the presence of transverse magnetic field.

This paper investigates the effects of thermal radiation on magneto hydrodynamic flow over a vertical plate with convective surface boundary condition. Section 2 presents the mathematical model of the problem. The numerical procedure is outlined in section 3 whilst results and discussions are presented in section 4. Section 5 presents some useful conclusions.

\section{Problem Formulation}

We consider a two-dimensional steady incompressible and electrically conducting fluid flow with heat transfer by convection over a vertical plate in the presence of radiation and magnetic field of strength, $B_{0}$, applied in the positive $y$ direction as shown in Figure 1. A stream of cold fluid at temperature $T_{\infty}$ moving over the right surface of the plate with a uniform velocity $U_{\infty}$ while the left surface of the plate is heated by convection from a hot fluid at temperature $T_{f}$, which provides a heat transfer coefficient $h_{f}$ (see Fig. 1).

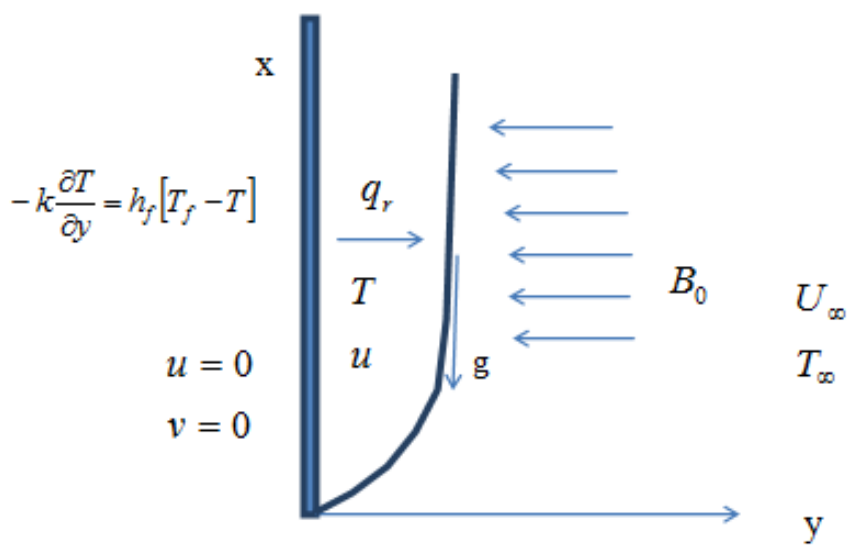

Fig. 1. Flow configuration and coordinate system

The induced magnetic field due to the motion of the electrically conducting fluid and the pressure gradient are neglected. The density variation due to buoyancy effects is taken into account in the momentum equation. The continuity, momentum, and energy equations describing the flow can be written as:

$$
\begin{gathered}
\frac{\partial \mathrm{u}}{\partial \mathrm{x}}+\frac{\partial \mathrm{v}}{\partial \mathrm{y}}=0 \\
\mathrm{u} \frac{\partial \mathrm{u}}{\partial \mathrm{x}}+\mathrm{v} \frac{\partial \mathrm{u}}{\partial \mathrm{y}}=v \frac{\partial^{2} \mathrm{u}}{\partial \mathrm{y}^{2}}+\mathrm{g} \beta\left(\mathrm{T}-\mathrm{T}_{\infty}\right)+\frac{\sigma \mathrm{B}_{0}^{2}}{\rho}\left(\mathrm{U}_{\infty}-\mathrm{u}\right) \\
\mathrm{u} \frac{\partial \mathrm{T}}{\partial \mathrm{x}}+\mathrm{v} \frac{\partial \mathrm{T}}{\partial \mathrm{y}}=\alpha \frac{\partial^{2} \mathrm{~T}}{\partial \mathrm{y}^{2}}+\frac{\sigma \mathrm{B}_{0}^{2}}{\rho \mathrm{c}_{\mathrm{p}}}\left(\mathrm{U}_{\infty}-\mathrm{u}\right)^{2}-\frac{\alpha}{\mathrm{k}} \frac{\partial \mathrm{q}_{\mathrm{r}}}{\partial \mathrm{y}}
\end{gathered}
$$

where $\mathrm{u}$ and $\mathrm{v}$ are the $\mathrm{x}$ (along the plate) and the $\mathrm{y}$ (normal to the plate) components of velocities respectively, $\mathrm{T}$ is the temperature, $v$ is the kinematics viscosity of the fluid, $\alpha$ is the thermal diffusivity of the fluid and $\beta$ is the thermal expansion coefficient. The corresponding boundary conditions can be expressed as:

$$
\begin{aligned}
& \mathrm{u}(\mathrm{x}, 0)=\mathrm{v}(\mathrm{x}, 0)=0,-\mathrm{k} \frac{\partial \mathrm{T}}{\partial \mathrm{y}}(\mathrm{x}, 0)=\mathrm{h}_{\mathrm{f}}\left[\mathrm{T}_{\mathrm{f}}-\mathrm{T}(\mathrm{x}, 0)\right] \\
& \mathrm{u}(\mathrm{x}, \infty)=\mathrm{U}_{\infty}, \mathrm{T}(\mathrm{x}, \infty)=\mathrm{T}_{\infty}
\end{aligned}
$$

\section{Numerical Procedure}

Using the Rosseland approximation for radiation, Ibrahim and Makinde [16] simplified the radiative heat flux as:

$$
\mathrm{q}_{\mathrm{r}}=-\frac{4 \sigma^{*}}{3 \mathrm{~K}^{\prime}} \frac{\partial \mathrm{T}^{4}}{\partial \mathrm{y}}
$$

Where $\mathrm{K}^{\prime}$ and $\sigma^{*}$ are the Stefan-Boltzmann constant and the mean absorption coefficient respectively. We assumed that the temperature differences within the flow such as the term T4 may be expressed as a linear function of temperature. Hence, expanding T4 in a Taylor series about $\mathrm{T} \infty$ and neglecting higher order terms, we get;

$$
\mathrm{T}^{4} \cong 4 \mathrm{~T}_{\infty}^{3} \mathrm{~T}-3 \mathrm{~T}_{\infty}^{4}
$$

Introducing a similarity variable $\eta$, a dimensionless stream function $\mathrm{f}(\eta)$ and dimensional temperature $\theta(\eta)$ as:

$$
\begin{aligned}
& \eta=\mathrm{y} \sqrt{\frac{\mathrm{U}_{\infty}}{v \mathrm{x}}}=\frac{\mathrm{y}}{\mathrm{x}} \sqrt{\mathrm{Re}_{\mathrm{x}}}, \theta(\eta)=\frac{\mathrm{T}-\mathrm{T}_{\infty}}{\mathrm{T}_{\mathrm{f}}-\mathrm{T}_{\infty}}, \\
& \frac{\mathrm{u}}{\mathrm{U} \infty}=\mathrm{f}^{\prime}, \quad \mathrm{v}=\frac{1}{2} \sqrt{\frac{\mathrm{U}_{\infty} v}{\mathrm{x}}}\left(\eta \mathrm{f}^{\prime}-\mathrm{f}\right),
\end{aligned}
$$

Equation (1) is satisfied simultaneously by defining the stream function in the usual way as:

$$
\mathrm{u}=\frac{\partial \psi}{\partial \mathrm{y}} \text { and } \mathrm{v}=-\frac{\partial \psi}{\partial \mathrm{x}}
$$

Equation (2) and (3) then reduces to:

$$
\mathrm{f}^{\prime \prime \prime}+\frac{1}{2} \mathrm{ff}^{\prime \prime}-\mathrm{M}\left(\mathrm{f}^{\prime}-1\right)+\mathrm{Gr}_{\mathrm{x}} \theta=0
$$




$$
\theta^{\prime \prime}\left(1+\frac{4}{3} \operatorname{Ra}\right)+\frac{1}{2} \operatorname{Pr} f f^{\prime \prime}+\operatorname{MEc} \operatorname{Pr}\left(1-f^{\prime}\right)^{2}=0
$$

The associated boundary conditions then become:

$$
\begin{aligned}
& \mathrm{f}^{\prime}(0)=\mathrm{f}(0)=0, \quad \theta^{\prime}(0)=-\mathrm{Bi}_{\mathrm{x}}(1-\theta(0)), \\
& \mathrm{f}^{\prime}(\infty)=0, \quad \theta(\infty)=0
\end{aligned}
$$

In the above equations, the prime symbol denotes differentiation with respect to $\eta, \operatorname{Re}=\mathrm{U}_{\infty} \mathrm{x} / v$ is the local Reynolds number, $\mathrm{Gr}_{\mathrm{x}}=\operatorname{xg} \beta\left(\mathrm{T}_{\mathrm{f}}-\mathrm{T}_{\infty}\right) / \mathrm{U}_{\infty}^{2}$ is the Grashof number, $\operatorname{Pr}=v / \alpha$ is the Prandtl number, $\mathrm{Ra}=4 \sigma^{*} \mathrm{~T}_{\infty}^{3} / \mathrm{KK}^{\prime}$ is the thermal radiation parameter, $\mathrm{M}=\sigma \mathrm{B}_{0}^{2} \mathrm{x} / \rho \mathrm{U}_{\infty}$ is the local magnetic field parameter, $\mathrm{Ec}=\mathrm{U}_{\infty}^{2} / \mathrm{C}_{\mathrm{p}}\left(\mathrm{T}_{\mathrm{f}}-\mathrm{T}_{\infty}\right)$ is the Eckert number and $\mathrm{Bi}_{\mathrm{x}}=\mathrm{h}_{\mathrm{f}} / \mathrm{k} \sqrt{\mathrm{Lx}_{\mathrm{x}} / \mathrm{U}_{\infty}}$ is the Biot number.

The coupled nonlinear equations (8) and (9) are observed to be of higher order and can be reduced to a set of first order differential equations by letting:

$$
f=x_{1}, f^{\prime}=x_{2}, f^{\prime \prime}=x_{3}, \theta=x_{4}, \theta^{\prime}=x_{5},
$$

Using equation (11), equations (8) and (9) are reduced to first order differential equations by letting:

$$
\begin{aligned}
& \mathrm{f}^{\prime}=\mathrm{x}_{1}^{\prime}=\mathrm{x}_{2}, \\
& \mathrm{f}^{\prime \prime}=\mathrm{x}_{2}^{\prime}=\mathrm{x}_{3}, \\
& \mathrm{f}^{\prime \prime \prime}=\mathrm{x}_{3}^{\prime}=-\frac{1}{2} \mathrm{x}_{1} \mathrm{x}_{3}-\mathrm{Gr}_{\mathrm{x}} \mathrm{x}_{4}+\mathrm{M}\left(\mathrm{x}_{2}-1\right), \\
& \theta^{\prime}=\mathrm{x}_{4}^{\prime}=\mathrm{x}_{5}, \\
& \theta^{\prime \prime}=\mathrm{x}_{5}^{\prime}=-\frac{1}{(1+4 \operatorname{Ra} / 3)}\left(\frac{1}{2} \operatorname{Pr} \mathrm{x}_{1} \mathrm{x}_{3}+\operatorname{MEc} \operatorname{Pr}\left(1-\mathrm{x}_{2}\right)^{2}\right),
\end{aligned}
$$

subject to the boundary conditions

$$
\begin{aligned}
& \mathrm{x}_{1}(0)=0, \mathrm{x}_{2}(0)=0, \mathrm{x}_{3}(0)=\mathrm{s}_{1}, \mathrm{x}_{4}(0)=1, \\
& \mathrm{x}_{5}(0)=\mathrm{s}_{2}, \mathrm{x}_{2}(\infty)=0, \mathrm{x}_{4}(\infty)=0,
\end{aligned}
$$

In the shooting method, the unspecified initial conditions; $\mathrm{s}_{1}$ and $\mathrm{s}_{2}$ in equation (13) were assumed and equation (12) integrated numerically as an initial valued problem to a given terminal point. The accuracy of the assumed missing initial conditions is checked by comparing the calculated value of the dependent variable at the terminal point with its given value there. If differences exist, improved values of the missing initial conditions are obtained and the process repeated. The computations were done by a written programme which uses a symbolic and computational computer language (MAPLE). A step size of $\Delta \eta=0.001$ was selected to be satisfactory for a convergence criterion of $10^{-7}$ in nearly all cases. The maximum value of $\eta_{\infty}$ to each group of parameters are determined when the values of unknown boundary conditions at $\eta_{\infty}=0$ not change to successful loop with error less than $10^{-7}$. From the process of numerical computations, the local skin-friction coefficient, the local Nusselt numbers and the local Sherwood numbers, which are respectively, proportional to $f^{\prime \prime}(0)$, and $-\theta^{\prime}(0)$ were worked out and their numerical values presented in tables.

\section{Results and Discussions}

Numerical results for different values of the thermophysical parameters controlling the fluid dynamics in the flow regime have been computed. The thermo-physical parameters considered in this study include: Prandtl number $(\mathrm{Pr})$, Biot number $\left(\mathrm{Bi}_{\mathrm{x}}\right)$, Grashof number $\left(\mathrm{Gr}_{\mathrm{x}}\right)$, Eckert number $(\mathrm{Ec})$, Radiation parameter $(\mathrm{Ra})$ and Magnetic field parameter (M).

\subsection{Numerical Results}

Numerical solution of the present work was compared with previous work by Makinde and Olanrewaju [17] and excellent agreement was obtained for Prandtl number $\mathrm{Pr}=0.72$ and Grashof number $\mathrm{Gr}_{\mathrm{x}}=0.1$. It is noteworthy that there was a perfect agreement in the absence of Magnetic field parameter $\mathrm{M}$, Eckert number $\mathrm{Ec}$ and Radiation parameter Ra.

The effects of various embedded thermo-physical parameters on the skin friction coefficient $(-\mathrm{f}(\theta))$, the rate of heat transfer $\left(-\theta^{\prime}(0)\right)$ represented by the local Nusselt number and the plate surface temperature $(\theta(0))$ are presented in Table 2 .

It is observed that increasing the Biot number from 0.1 to 10 increases the skin friction coefficient, rate of heat transfer and plate surface temperature due to an increase in convective heating of the surface. Also, increasing the Grashof number from 0.1 to 1.5 increases the skin friction coefficient and the rate of heat transfer but decreases the plate surface temperature due to buoyancy forces. Furthermore, increasing the Prandtl number from 0.72 to 7.1 decreases the skin friction coefficient but increases the rate at which heat is transferred at the surface of the plate due to an increase in convective heat exchange at the surface of the plate. Moreover, it is worth noting that, increasing the magnetic field parameter from 1 to 5 , Eckert number from 0.1 to 2.0 and radiation parameter from 0.1 to 3.0 , increase the magnitude of skin friction coefficient and surface plate temperature due to Ohmic heating of the fluid but decreases the rate at which heat is transferred at the surface of the plate as a result of a distractive force known as Lorentz force. 
Table 1. Computations showing comparison with Makinde and Olanrewaju [17] results for Grx=0.1, Pr=0.72, M=0, Ec=0 and Ra=0.

\begin{tabular}{llllcccc}
\hline \multirow{2}{*}{ Bix } & \multicolumn{5}{l}{ Makinde and Olanrewaju [17] } & \multicolumn{5}{c}{ Present Study. } \\
\cline { 2 - 7 } & $\mathrm{f}^{\prime \prime}(0)$ & $-\theta^{\prime}(0)$ & $\theta(0)$ & $\mathrm{f}^{\prime \prime}(0)$ & $-\theta^{\prime}(0)$ & $\theta(0)$ \\
\hline 0.1 & 0.36881 & 0.07507 & 0.24922 & 0.36882 & 0.07508 & 0.24923 \\
1.0 & 0.44036 & 0.23750 & 0.76249 & 0.44037 & 0.23751 & 0.76249 \\
10 & 0.46792 & 0.30559 & 0.96944 & 0.46793 & 0.30560 & 0.96944 \\
\hline
\end{tabular}

Table 2. Computation showing $\mathrm{f}^{\prime \prime}(0),-\theta^{\prime}(0)$ and $\theta(0)$ for different parameter values.

\begin{tabular}{|c|c|c|c|c|c|c|c|c|}
\hline Bix & Grx & $\operatorname{Pr}$ & $\mathbf{M}$ & Ec & $\mathbf{R a}$ & $f^{\prime \prime}(0)$ & $-\theta^{\prime}(0)$ & $\theta(0)$ \\
\hline 0.1 & 0.1 & 0.72 & 1 & 0.1 & 0.1 & 1.064044 & 0.072100 & 0.279002 \\
\hline 1.0 & 0.1 & 0.72 & 1 & 0.1 & 0.1 & 1.097484 & 0.240794 & 0.759206 \\
\hline 10 & 0.1 & 0.72 & 1 & 0.1 & 0.1 & 1.111997 & 0.315061 & 0.968494 \\
\hline 0.1 & 0.5 & 0.72 & 1 & 0.1 & 0.1 & 1.140550 & 0.072852 & 0.271476 \\
\hline 0.1 & 1.0 & 0.72 & 1 & 0.1 & 0.1 & 1.229590 & 0.073634 & 0.263660 \\
\hline 0.1 & 1.5 & 0.72 & 1 & 0.1 & 0.1 & 1.313044 & 0.074286 & 0.257141 \\
\hline 0.1 & 0.1 & 1.00 & 1 & 0.1 & 0.1 & 1.062553 & 0.073046 & 0.269541 \\
\hline 0.1 & 0.1 & 3.00 & 1 & 0.1 & 0.1 & 1.060202 & 0.072670 & 0.273296 \\
\hline 0.1 & 0.1 & 7.10 & 1 & 0.1 & 0.1 & 1.060103 & 0.067703 & 0.322967 \\
\hline 0.1 & 0.1 & 0.72 & 2 & 0.1 & 0.1 & 1.461228 & 0.070333 & 0.296671 \\
\hline 0.1 & 0.1 & 0.72 & 3 & 0.1 & 0.1 & 1.771515 & 0.068835 & 0.311655 \\
\hline 0.1 & 0.1 & 0.72 & 5 & 0.1 & 0.1 & 2.267967 & 0.066308 & 0.336916 \\
\hline 0.1 & 0.1 & 0.72 & 1 & 1.0 & 0.1 & 1.100615 & 0.025469 & 0.745315 \\
\hline 0.1 & 0.1 & 0.72 & 1 & 1.5 & 0.1 & 1.119508 & 0.001144 & 0.988558 \\
\hline 0.1 & 0.1 & 0.72 & 1 & 2.0 & 0.1 & 1.137541 & -0.022219 & 1.222185 \\
\hline 0.1 & 0.1 & 0.72 & 1 & 0.1 & 1.0 & 1.068662 & 0.068569 & 0.314306 \\
\hline 0.1 & 0.1 & 0.72 & 1 & 0.1 & 2.0 & 1.072411 & 0.065517 & 0.344828 \\
\hline 0.1 & 0.1 & 0.72 & 1 & 0.1 & 3.0 & 1.075199 & 0.063218 & 0.367823 \\
\hline
\end{tabular}

\subsection{Graphical Results}

\subsubsection{Effects of Parameter Variation on the Velocity Profiles}

Figures $2-4$ present the velocity profiles for varying parameters. Generally, the velocity starts from a zero value at the plate surface and increases to the free stream value far away from the plate surface satisfying the far field boundary conditions for all parameter values. In Figures 2 and 3, it is observed that increasing the Eckert number and Grashof number increases the velocity boundary layer thickness which peaks near the surface at $\eta=2$. Furthermore, it is observed in Figure 4 that increasing the intensity of the magnetic field parameter decreases the velocity longitudinally with all profiles tending asymptotically to the free stream value away from the plate.

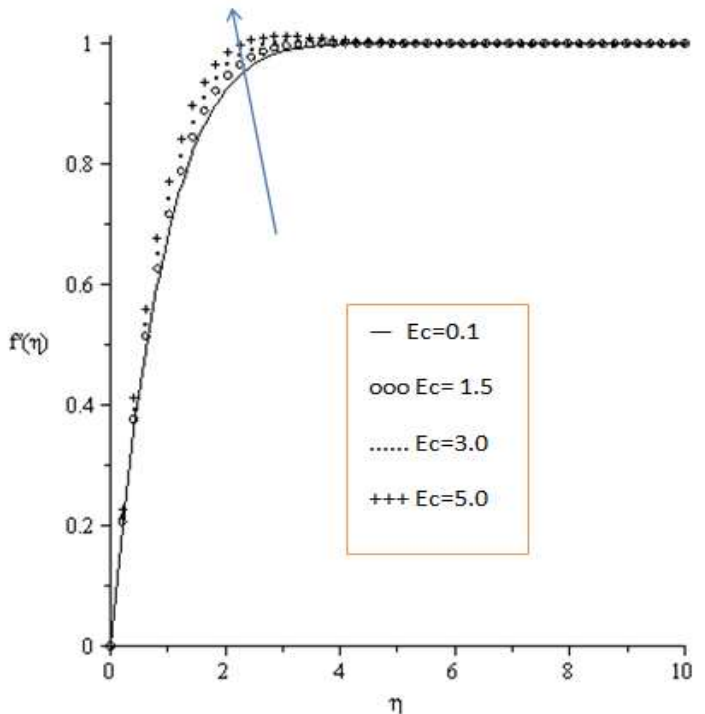


Figure 2. Velocity Profiles for increasing Eckert number.

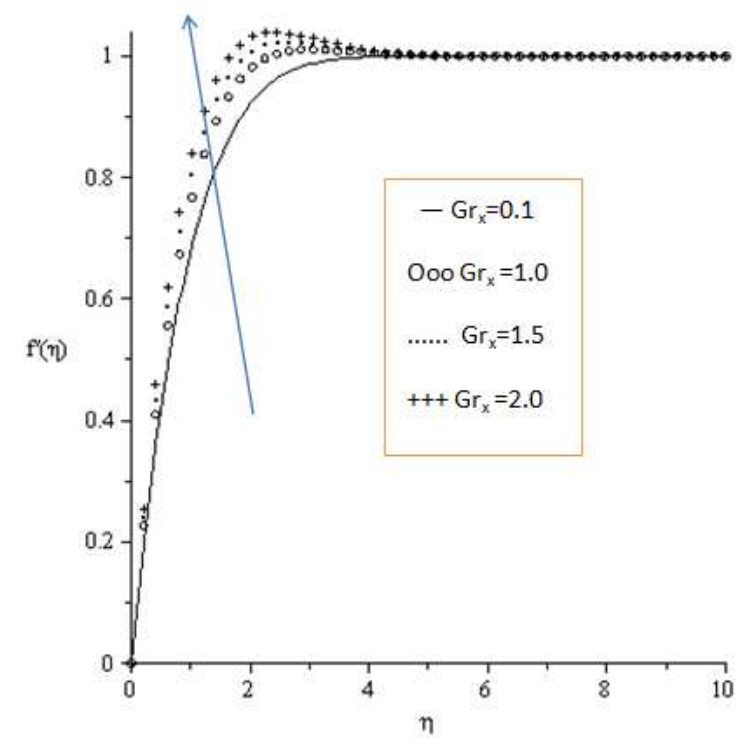

Figure 3. Velocity Profiles for increasing Grashof number.

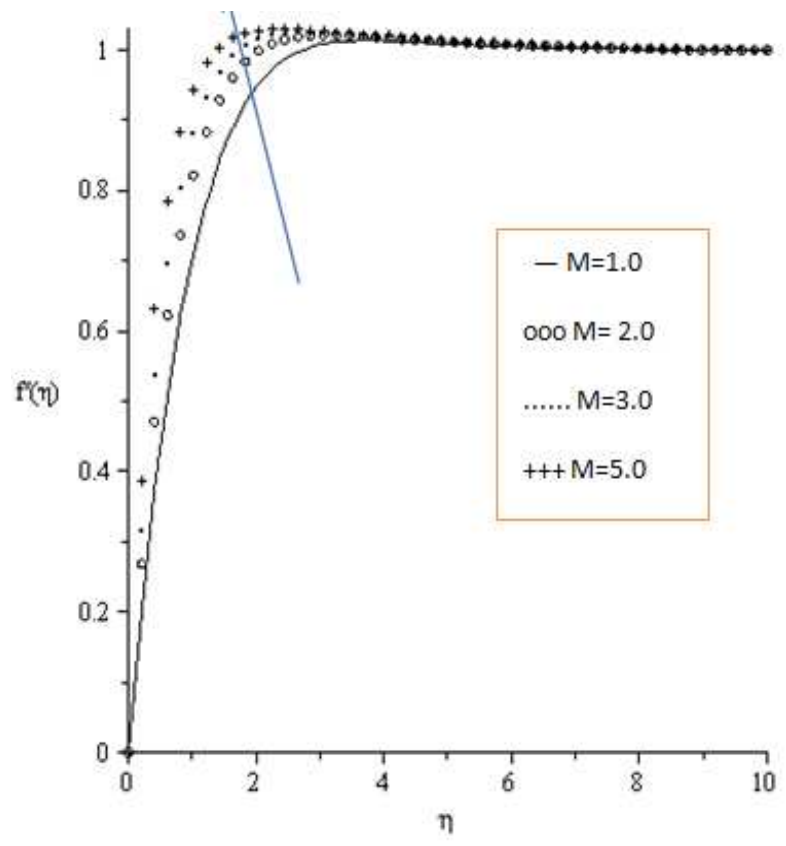

Figure 4. Velocity Profiles for increasing Magnetic field parameter.

\subsubsection{Effects of Parameter Variation of Temperature Profiles}

Figures $5-10$ present the temperature profiles for various parameter variations. Generally, the temperature of the fluid reaches its maximum at the surface of the plate and decreases exponentially to the free stream zero value away from the plate where it attained its minimum, satisfying the boundary condition. In figure 5, the thermal boundary layer thickness increases as the Biot number is increased. Also, it is observed in figures 6,8 and 10 that increasing the Eckert number, magnetic field parameter and radiation parameter increase the fluid temperature thereby increasing the thermal boundary layer thickness. Moreover, it is noted in figures 7 and 9 that increasing the Grashof and Prandtl numbers decrease the thermal boundary layer thickness far from the boundary.

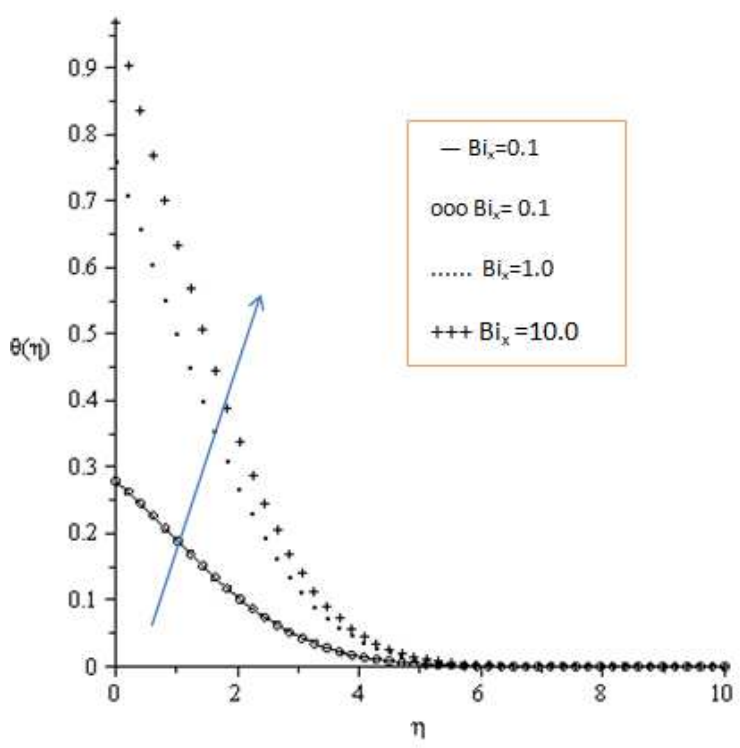

Figure 5. Temperature Profiles for varying Biot number.

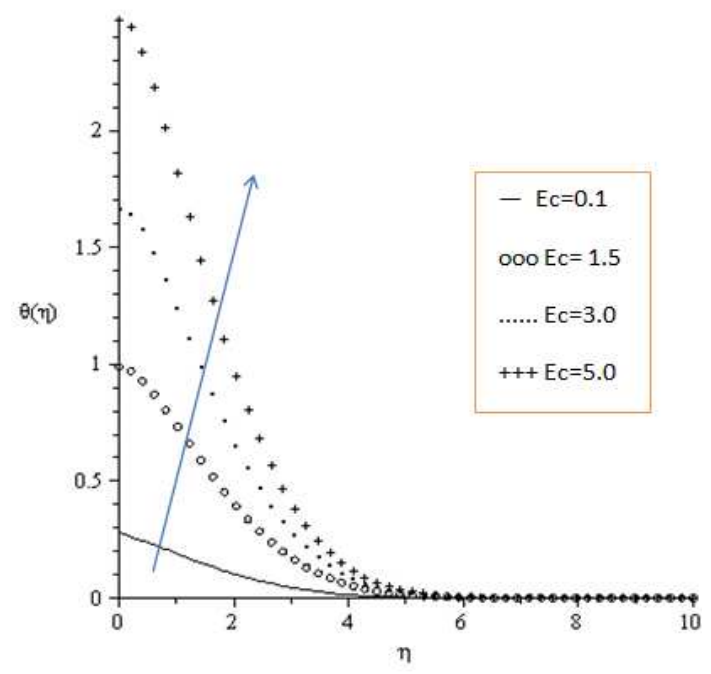

Figure 6. Temperature Profiles for varying Eckert number. 


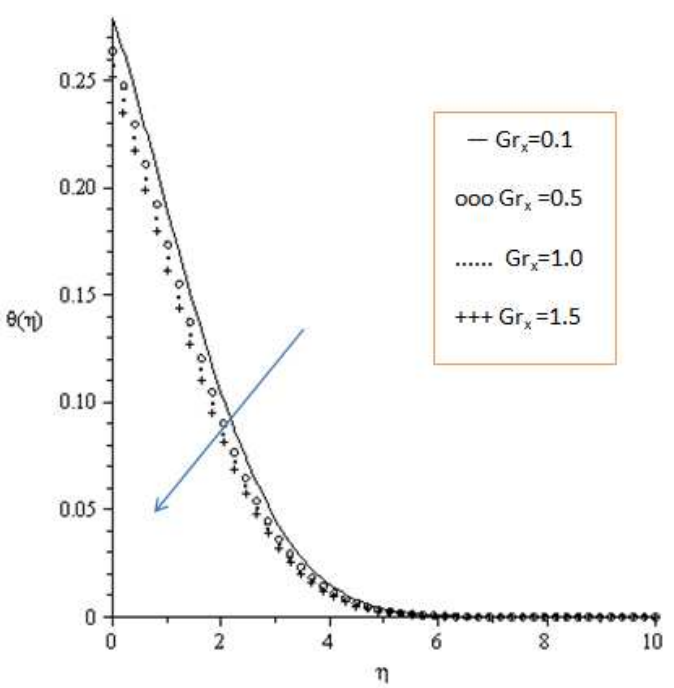

Figure 7. Temperature Profiles for varying Grashof number.

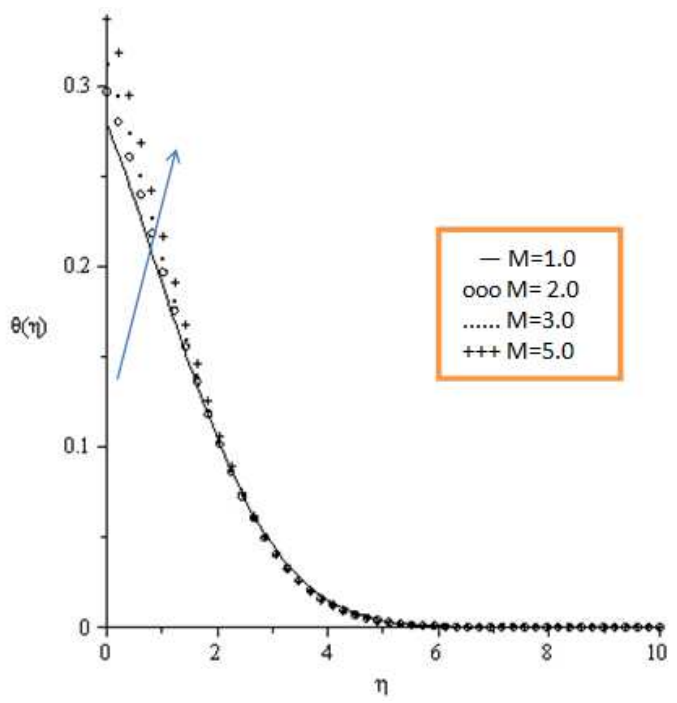

Figure 8. Temperature Profiles for varying Magnetic field parameter.

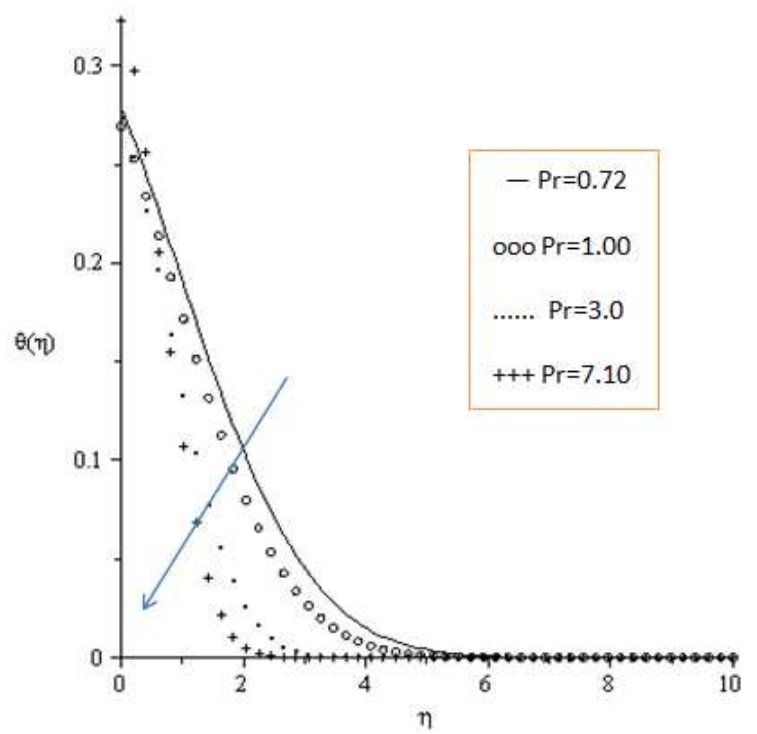

Figure 9. Temperature Profiles for varying Prandtl number.

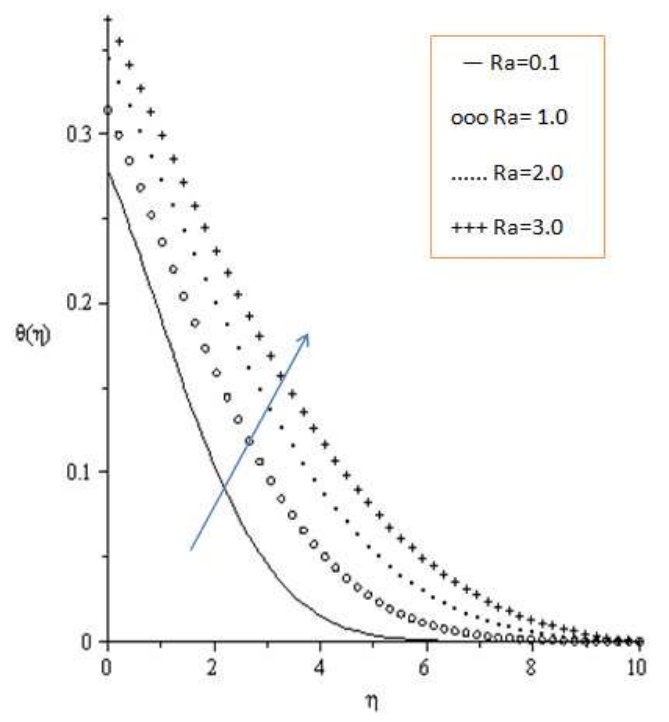

Figure 10. Temperature Profiles for varying Radiation parameter.

\section{Conclusions}

In this study, the effect of radiation on magneto hydrodynamic flow over a vertical plate with convective surface boundary condition was investigated. The nonlinear and coupled governing differential equations were solved numerically using the fourth order Runge-Kutta algorithm with a shooting method. Numerical results were presented whilst the velocity and temperature profiles illustrated graphically and analyzed. The following conclusions can be made.

- Increasing the Eckert number, radiation parameter and magnetic field parameter increase the skin friction coefficient and plate surface temperature but decrease the rate at which heat is transferred at the surface of the plate.

- Increasing the Biot number, increases the skin friction coefficient, rate of heat transfer and plate surface temperature

- Increasing the Eckert number, Grashof number and Magnetic field parameter increase the velocity boundary layer thickness.

- Increasing the Biot number, Eckert number, Magnetic field parameter and Radiation parameter increase the thermal boundary layer thickness. However, increasing the Grashof and Prandtl numbers decrease the thermal boundary layer thickness of the fluid flow.

\section{Nomenclature}

$(\mathrm{x}, \mathrm{y})=$ Cartesian coordinates

$(\mathrm{u}, \mathrm{v})=$ Velocity components

$\mathrm{T}_{\infty}=$ Freestream temperature

$\mathrm{T}_{\mathrm{f}}=$ Hot fluid temperature

$\mathrm{g}=$ Gravitational acceleration

$\mathrm{T}=$ Fluid temperature

Pr $=$ Prandtl number 
$\mathrm{U}_{\infty}=$ Freestream velocity

$\mathrm{Gr}_{\mathrm{x}}=$ Local Grashof number

$\mathrm{Bi}_{\mathrm{x}}=$ Local convective heat transfer parameter (Biot number)

$\mathrm{Ec}=$ Eckert number

$\mathrm{Ra}=$ Radiation parameter

$\mathrm{M}=$ Magnetic field parameter

$k=$ Thermal conductivity

$\mathrm{q}_{\mathrm{r}}=$ Radiative heat flux

$\mathrm{C}_{\mathrm{p}}=$ Specify heat at constant pressure

$\mathrm{Re}=$ Reynolds number

$\mathrm{K}^{\prime}=$ The Stefan-Boltzmann constant

Greek Symbols

$\alpha=$ Thermal diffusivity of the fluid

$\beta=$ Thermal expansion coefficient

$v=$ Kinematic viscosity

$\sigma^{*}=$ The mean absorption coefficient

\section{References}

[1] S.O. Ajadi, A. Adegoke, A. Aziz, Slip Boundary Layer Flow of non-Newtonian Fluid over a Flat Plate with Convective Thermal Boundary Condition. International Journal of Nonlinear Science, 8 (3), 2009,300-306

[2] M.S. Abel and M. Mareppa, MHD flow and heat transfer of the mixed hydrodynamic / thermal slip over a linear vertically stretching sheet International Journal of Mathematical Archive-4(5), 2013, 156-163

[3] Y.I. Seini and O.D. Makinde, Hydromagnetic Flow with Dufour and Soret Effects past a Vertical Plate Embedded in Porous Media, Mathematical Theory and Modeling, 3 (12), 2013, $47-64$

[4] M. Abbasi, G.H. Navab, I.R. Petroudi, Analytic solution of hydrodynamic and thermal boundary layers over a flat plate in a uniform stream of fluid with convective surface boundary condition. Indian J. Sci. Res. 1(2), 2014, 241-247.

[5] O.D. Makinde, Similarity solution of hydromagnetic heat and mass transfer over a vertical plate with a convective surface boundary condition International Journal of the Physical Sciences Vol. 5(6), 2010, 700-710.

[6] O.D. Makinde and A. Ogulu, The effect of thermal radiation on the heat and mass transfer flow of a variable viscosity fluid past a vertical porous plate permeated by a transverse magnetic field, Chem. Eng. Commun. 195(12), 2008, 15751584 .
[7] A.Y. Ghaly and E.M.E. Elbarbary, Radiation effect on MHD free convection flow of a gas at a stretching surface with uniform free stream, J. Appl. Math., 2, 2002, 93

[8] A.M. Emad, Radiation effect on heat transfer in an electrically conducting fluid at a stretching surface with uniform free stream, J. Phys. D., Appl. Phys. 33, 2000, 3180.

[9] M.E. Yazdi, A. Moradi and S. Dinarvand, Radiation Effects on MHD Stagnation-Point Flow in a Nanofluid, Research Journal of Applied Sciences, Engineering and Technology 5(22), 2013, 5201-5208

[10] M.K. Mazumdar and R.K. Deka, MHD flow past an impulsively started infinite vertical plate in presence of thermal radiation, Romanian Journal of Physics, 52(5-6), 2007, 529-535

[11] S. Srinivas and R. Muthuraj, Effects of thermal radiation and space porosity on MHD mixed convection flow in a vertical channel using homotopy analysis method Fluid Dynamics Division, Communication in Nonlinear Science and Numerical Simulation, 15(8), 2010, 2098-2108.

[12] M.A. Emmanuel, I.Y. Seini, A. Seidu, On chemically reacting hydromagnetic flow over a flat surface in the presence of radiation with viscous dissipation and convective boundary conditions, American Journal of Applied Mathematics, 2 (5), 2014, 179-185

[13] M. A. Hossain and H. S. Takhar, "Radiation effect on mixed convection along a vertical plate with uniform surface temperature", Heat mass transfer 31, 1996, 243 - 248.

[14] R. Imoro, E.M. Arthur and Y.I. Seini, Heat and Mass Transfer over a Vertical Surface with Convective Boundary Conditions in the Presence of Viscous Dissipation and nth Order Chemical Reaction. International Journal of Computational and Applied Mathematics, RIP. ISSN 1819-4966 Volume 9, Number 2, 2014, pp. 101-118.

[15] Y.I. Seini and O.D Makinde, Boundary layer flow near stagnation-points on a vertical surface with slip in the presence of transverse magnetic field. International Journal of Numerical Methods for Heat \& Fluid Flow Vol. 24 No. 3, 2014, pp. 643-653.

[16] S.Y. Ibrahim and O.D. Makinde, "MHD boundary layer flow due to exponential stretching surface with radiation and chemical reaction", Mathematical Problems in Engineering, 2013. http://dx.doi.org/10.1155/2013/163614

[17] O. D. Makinde and P. O. Olanrewaju, Buoyancy Effects on Thermal Boundary Layer Over a Vertical Plate With a Convective Surface Boundary Condition. Journal of Fluids Engineering, 2010, Vol. 132 / 044502-1 